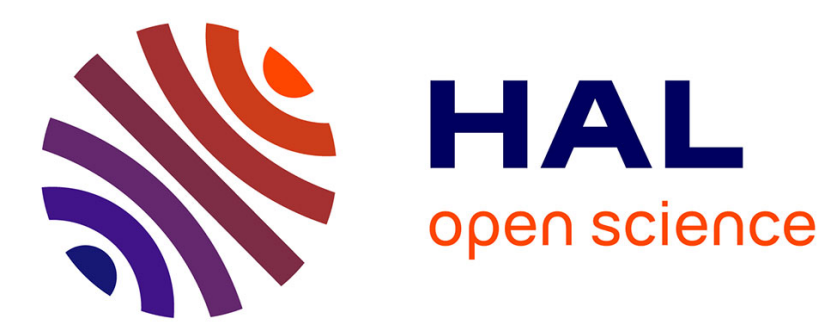

\title{
Interfaces and interfacial mechanics : influence on the mechanical behavior of ceramic matrix composites (CMC)
}

\author{
J. Lamon
}

\section{- To cite this version:}

J. Lamon. Interfaces and interfacial mechanics: influence on the mechanical behavior of ceramic matrix composites (CMC). Journal de Physique IV Proceedings, 1993, 03 (C7), pp.C7-1607-C7-1616. 10.1051/jp4:19937252 . jpa-00251891

\section{HAL Id: jpa-00251891 https://hal.science/jpa-00251891}

Submitted on 1 Jan 1993

HAL is a multi-disciplinary open access archive for the deposit and dissemination of scientific research documents, whether they are published or not. The documents may come from teaching and research institutions in France or abroad, or from public or private research centers.
L'archive ouverte pluridisciplinaire HAL, est destinée au dépôt et à la diffusion de documents scientifiques de niveau recherche, publiés ou non, émanant des établissements d'enseignement et de recherche français ou étrangers, des laboratoires publics ou privés. 


\title{
Interfaces and interfacial mechanics: influence on the mechanical behavior of ceramic matrix composites (CMC)
}

\section{J. LAMON}

Laboratoire des Composites Thermostructuraux, UMR - 47 CNRS-SEP-UB1, 3 allée de la Boëtie, 33600 Pessac, France

\begin{abstract}
The influence of fiber/matrix interactions on the mechanical behavior of ceramic matrix composites is examined on glass matrix composites and mainly on composites made by chemical vapor infiltration (CVI) of a fiber preform by a $\mathrm{SiC}$ matrix. Then the relationships between interfaces and features of the stress-strain behavior are highlighted on microcomposite specimens using experimental data and predictions from a model based upon fracture statistics. Finally the incidence of interfaces on fracture toughness is discussed on $2 \mathrm{D} \mathrm{SiC/SiC} \mathrm{composites.} \mathrm{It} \mathrm{is} \mathrm{shown} \mathrm{that} \mathrm{rather}$ strong interfaces provide both strong and tough $2 \mathrm{D}$ woven fiber reinforced composites.
\end{abstract}

\section{INTRODUCTION}

It is well acknowledged that fiber/matrix interactions exert a profound influence on the mechanical behavior of composites. Therefore, it may be expected that composites could be tailored as a function of end use applications through optimization of fiber/matrix interfaces.

Fiber/matrix interfaces are the locus of fibre/matrix interactions. Fiber/matrix bonding results from diffusion or chemical reactions (chemical bonding) or from fibre fretting by residual stresses induced by thermal expansion mismatch. Fiber/matrix interfaces in the most advanced materials consist of a thin coating layer (less than $1 \mu \mathrm{m}$ thick), of one or several materials deposited on the fiber. Experimental data have shown that the mechanical behavior of composites is essentially brittle in the absence of an interfacial material.

Current methods used for measuring interfacial properties provide a shear strength or a sliding shear stress. They consist in pulling or pushing the fibre out of the matrix [13].

Two key functions may be assigned to fiber/matrix interfaces : strengthening and toughening of composites. Strengthening results from load transfers whereas 
toughening is induced by energy absorption processes. It is often considered that toughening is a major issue in CMC. On the basis of analyses conducted on unidirectional ceramic matrix composites most authors propose crack bridging and fiber pull out as major contributions to toughness [4]. Reather weak fiber/matrix interfaces are therefore required.

Conversely toughening involves a dense network of matrix cracks, that form a process zone ahead of the main crack [5-6] in those CVI composites reinforced with plies of woven fiber bundles. Matrix cracking is favored by limited debonding and strong fiber/matrix interactions for further loading of the matrix blocks.

Nevertheless, a high strength is also an important issue in CMC. Efficient load transfers, necessitate rather strong fiber/matrix interactions.

The main purpose of the present paper is therefore to discuss the influence of interfacial properties on the stress-strain behavior and fracture toughness of CMC. Results available in the literature for glass matrix composites are used. However focus is placed upon data generated on $\mathrm{SiC}$ matrix fiber reinforced composites made by chemical vapor infiltration [7].

\section{INTERACTIONS BETWEEN FIBER AND MATRIX : BASIC FEATURES}

Interactions between fiber and matrix involve the misfit strain induced by respective fiber and matrix properties, as well as interfacial properties. Interactions between fibers and matrix are very complex. The stress-strain curves of composites have been coupled to some basic features of debonding and sliding at the interface between fiber and matrix $[4,8]$. Some simple rules of crack interaction with fibers have been proposed by authors in the literature. These rules are supported by a certain amount of experimental observations.

Initial debonding is a prerequisite to composite toughness and strength. In the absence of debonding, cracks that initiated in the matrix propagate catastrophically through the fibers. The resulting composite is thus essentially brittle. The knowledge generated by the models based upon mechanics of bimaterials indicates that initial debonding along the interface is governed by the relative debond toughness $\Gamma_{\mathrm{i}} / \Gamma_{\mathrm{f}}[9]$ (where $\Gamma_{\mathrm{i}}$ and $\Gamma_{\mathrm{f}}$ refer respectively to the interface and to the fiber).

Crack opening at increasing applied stresses may cause propagation of interfacial cracks. Crack opening is accompanied by fiber sliding along the debonded interface. The importance of this sliding phenomenon is related to the misfit strain, to fiber surface roughness and to debond length.

Failure of fibers is dictated by debond length and by crack/fiber interactions. Stresses in the fiber decrease along the debond length. Small debond lengths cause fiber stress to vary rapidly with the distance from the matrix cracks. Fiber fracture is determined by severity of the flaws preexisting within the fibers. It involves the statistics of fiber failure. It is governed by the stressed volume and stress magnitude. The larger the stressed volume the lower the failure stresses. Therefore, fracture stress decrease should be expected at increasing debond. The most probable failure origin is located close to the matrix crack in the presence of limited debond lengths. Remote failure sites require important debonding.

Pull out of broken fibers involves sliding along the debonded interfaces. Toughening is therefore dictated by frictional sliding which enhances energy dissipation as heat. The 
sliding distance is determined by the failure site location. Frictional sliding is determined by fiber/crack interactions. The sliding resistance $\tau$ influences the pull out length and this controls the toughness. As $\tau$ decreases, pull out length increases rapidly and toughness increases.

\section{INFLUENCE OF INTERFACES ON THE STRESS-STRAIN BEHAVIOR OF CERAMIC MATRIX COMPOSI'TES}

\section{Practical CMC}

Examples of stress-strain behaviors measured in tension for practical unidirectionnal glass matrix composites and $2 \mathrm{D}$ woven $\mathrm{SiC}$ matrix composites are shown on figures 1 and 2.

These behaviors exhibit a typical non-linear domain attributed to multiple cracks created in the matrix and deflected by fibers into fiber/matrix interfaces. In some cases, a "hardening" domain is also present. This linear domain is dominated by opening of the matrix cracks and elastic deformation of the fibers. It is worth noting that instead of a pull out tail indicative of fiber pull out, load dropped abruptly at ultimate strength. The three important basic features of the stress strain curves exhibited by real CMC are therefore the stresses at matrix cracking $\left(\sigma_{\mathrm{p}}\right)$ and at saturation $\left(\sigma_{\mathrm{S}}\right)$ that measure the extent of the non-linear domain, and the ultimate strength $\left(\sigma_{R}\right)$ determined by fiber bundle failure.

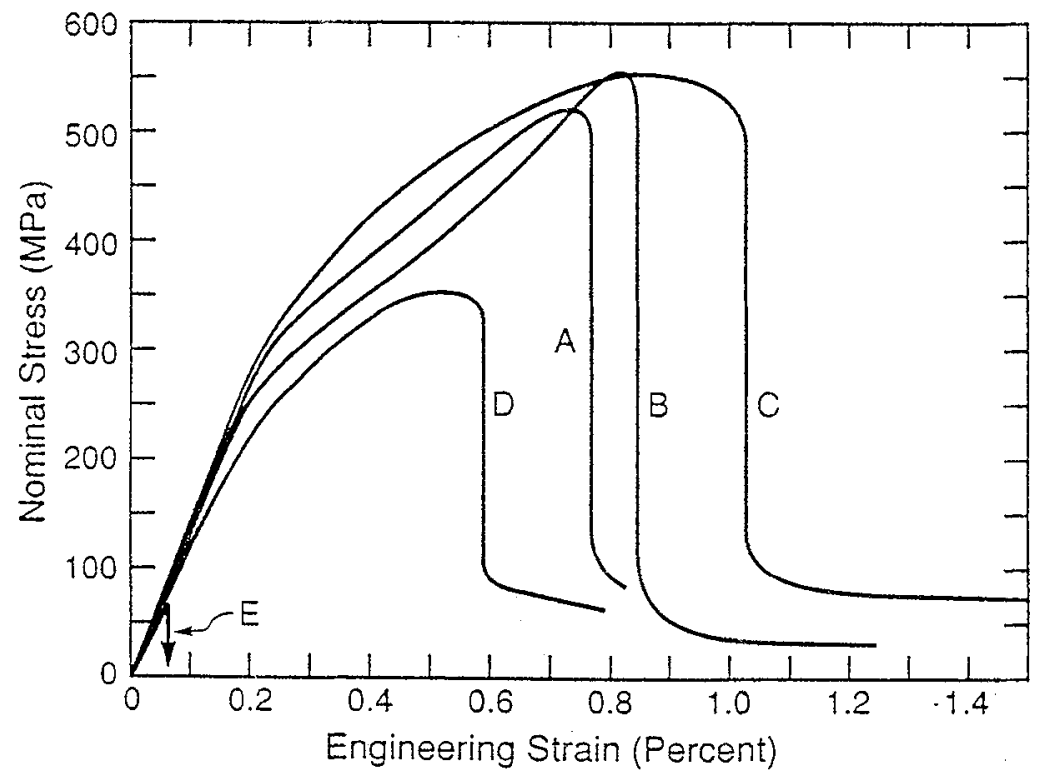

Figure 1: Tensile stress-strain curves measured for various glass matrix Nicalon fiber reinforced composites [10]. 


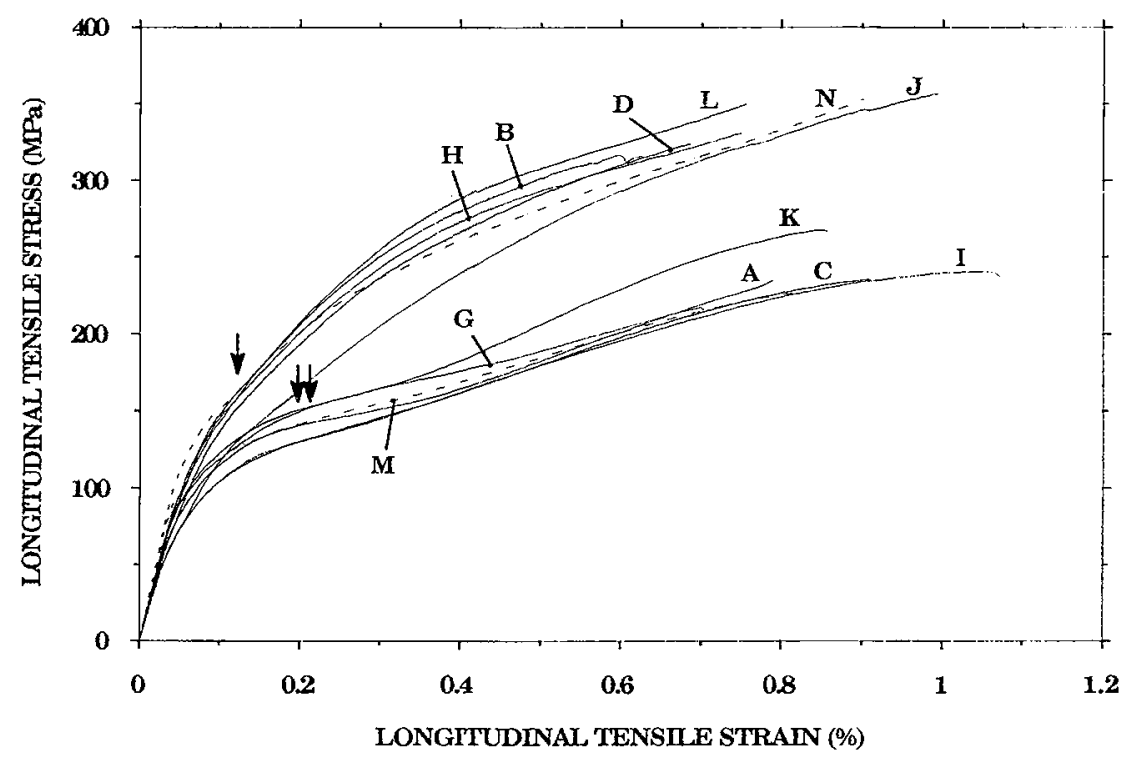

Figure 2: Tensile stress-strain curves for 2D-SiC/SiC CVI-composites possessing various interphases.

The stress-strain behaviors shown on figures 1 and 2 are grouped into two distinct families as a function of the extent of the non-linear domain and stress magnitude :

- first, the low stress curves exhibiting a limited non-linear domain and conversely, a significant hardening domain (for the $\mathrm{A}$ and $\mathrm{B}$ glass matrix composites and the A, C, G, I, K, M SiC-matrix CVI-composites).

- then the high stress curves exhibiting an important non-linear domain (for the $\mathrm{C}$ and $\mathrm{D}$ glass matrix composites and the B, D, H, J, L, N SiC-matrix CVI-composites). The hardening domain is generally absent $\left(\sigma_{\mathrm{S}}\right.$ coincides with $\sigma_{\mathrm{R}}$ ).

\begin{tabular}{|c|c|c|c|c|}
\hline Désignation & Matrix & Interphase & $\begin{array}{c}1_{\mathrm{s}} \\
(\mu \mathrm{m})\end{array}$ & $\begin{array}{c}\tau \\
(\mathrm{MPa})\end{array}$ \\
\hline $\mathrm{A}$ & $\begin{array}{c}\text { LAS III } \\
\text { glass-ceramic } \\
\text { B }\end{array}$ & $\mathrm{C}$ & 400 & 2 \\
$\mathrm{C}$ & LAS III glass & $\mathrm{C}$ & 120 & 7 \\
$\mathrm{D}$ & Alunimosilicate & $\mathrm{C}$ & 90 & 9 \\
$\mathrm{E}$ & Soda-lime glass & $\begin{array}{c}\text { Complex } \\
(\mathrm{C}, \mathrm{O}, \mathrm{B}, \mathrm{Si}, \mathrm{Ca}, \mathrm{Na})\end{array}$ & 70 & 12 \\
\hline
\end{tabular}

Table 1: Experimental data on interactions between fibers and matrix measured by Cao and coworkers [10] for the glass matrix Nicalon fiber composites of figure 1 . 


\begin{tabular}{|c|c|c|c|c|c|}
\hline Materials & $\begin{array}{l}\sigma_{\mathrm{r}} \\
(\mathrm{MPa})\end{array}$ & $\begin{array}{l}\sigma_{\mathrm{p}} \\
(\mathrm{MPa})\end{array}$ & $\begin{array}{c}\sigma_{\mathrm{s}} \\
(\mathrm{MPa})\end{array}$ & $\begin{array}{l}\mathrm{l}_{\mathrm{s}} \\
(\mu \mathrm{m})\end{array}$ & $\begin{array}{c}\tau \\
(\mathrm{MPa})\end{array}$ \\
\hline $\mathrm{A}$ & $235^{*}$ & 140 & 155 & 340 & 2 \\
\hline $\mathrm{B}$ & $317^{*}$ & 140 & $\approx \sigma_{\mathrm{r}}$ & 30 & 150 \\
\hline $\mathrm{C}$ & 235 & 130 & 155 & 230 & 3 \\
\hline $\mathrm{D}$ & 324 & 150 & $\approx \sigma_{\mathrm{r}}$ & 30 & 70 \\
\hline $\mathrm{G}$ & 217 & 160 & 180 & 150 & 6 \\
\hline $\mathrm{H}$ & 331 & 150 & $\approx \sigma \mathrm{r}$ & 110 & 34 \\
\hline $\mathrm{I}$ & 241 & 125 & 145 & 185 & 4 \\
\hline $\mathrm{J}$ & $356^{*}$ & 140 & $\approx \sigma \mathrm{r}$ & 20 & 370 \\
\hline $\mathrm{K}$ & 267 & 150 & 170 & 115 & 9 \\
\hline $\mathrm{L}$ & $350^{*}$ & 150 & 345 & 30 & 90 \\
\hline $\mathrm{M}$ & 226 & 145 & 165 & 360 & 2 \\
\hline $\mathrm{N}$ & 353 & 150 & 330 & 20 & 210 \\
\hline
\end{tabular}

* : premature failure

Table 2: Features of the stress-strain behavior against interfacial resistance for 2D$\mathrm{SiC} / \mathrm{SiC}$ CVI-composites with various interphases

This classification correlates with ranking of interfacial resistances as measured by the sliding stress $\tau$ and the crack spacing distance at saturation $l_{\mathrm{S}}$ (tables 1 and 2 ).

Table 2 also clearly indicates that extent of non-linear domain reflected by the saturation data relative to ultimate failure is commensurate with interfacial resistance.

\section{Elementary cell : microcomposites}

The influence of interfaces is perfectly highlighed by the stress-strain behavior of microcomposite specimens. Microcomposites represent the elementary cell of composites. They consist of a single fiber coated with an interfacial material and then embedded into a SiC matrix deposited by CVD [3]. Typical stress-strain curves obtained with a range of microcomposites possessing various interfacial properties are shown on figure 3 [11]. It is worth noting that these curves exhibit the typical features previously discussed on practical CMC : non-linearity induced by matrix cracking and debonding, and a hardening domain dominated by matrix crack opening and deformation of the fiber. In some cases, matrix cracking and debonding are marked by load drops. 
Of particular interest for illustration of the strong dependence of stress-strain behavior upon interfacial failure, is the behavior exemplified by figure 4. This load-displacement curve was obtained with a SiC/SiC microcomposite possessing a weak Carbon interphase $\left(\tau=5 \mathrm{MPa}\right.$, debond length $l_{\mathrm{d}}=1 \mathrm{~mm}$ [12]). This curve consists of linear segments with a slope decreasing as matrix cracks form. Matrix cracking events are evidenced by acoustic emission. At ultimate failure, an abrupt load drop generally occurs. A significant pull out tail was observed with a few microcomposites only.

Analysis of the load displacement curves allows extraction of interfacial characteristics such as $l_{d}, \tau$ and interfacial fracture energy $[3,11,12]$.

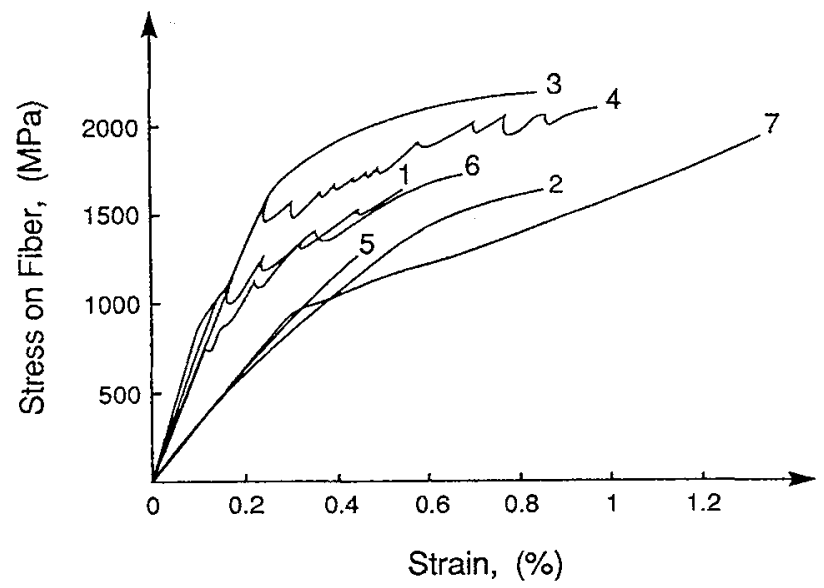

Figure 3: Stress-strain behavior obtained on different $\mathrm{SiC} / \mathrm{SiC}$ microcomposite specimens with a range of $B N$ interfaces.

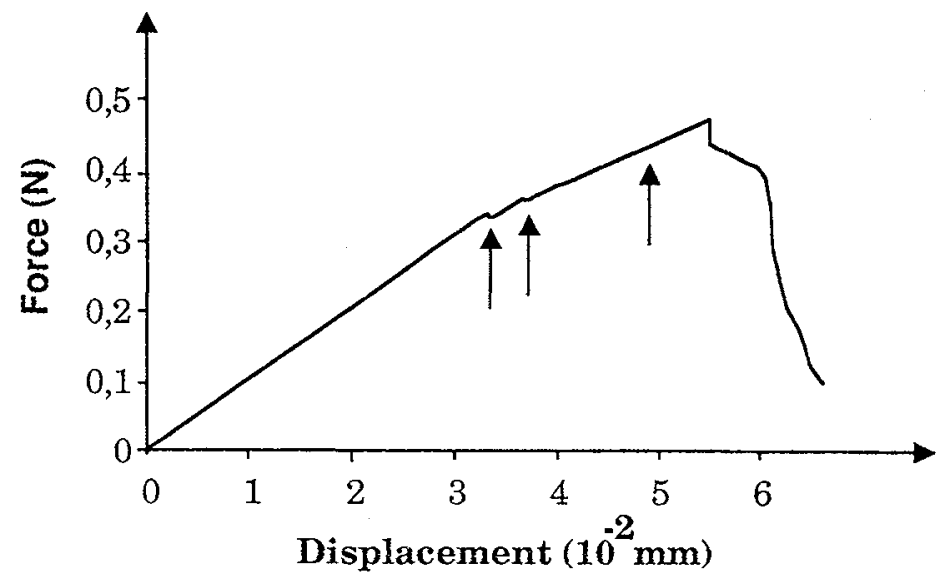

Figure 4: Typical load-displacement curve obtained for a $\mathrm{SiC} / \mathrm{SiC}$ microcomposite with a rather weak $\mathrm{C}$ interphase (thickness $1 \mu \mathrm{m}$ ). 


\section{Predictions of the influence of interfaces on the stress-strain behavior}

The above trends are quantitatively described on figures 5 which represents a plot of extent of non-linearity (as measured by $\sigma_{R}-\sigma_{S}$ ) and associated quantity of matrix cracks at saturation as a function of debond length. These data were predicted using a probabilistic model of microcomposite damage and failure [13].

Matrix failure and then ultimate fiber failure which appeared as successive non interactive brittle events occurring sequentially (figures 3 and 4) were modelled using weakest-link concept based fracture statistics. It was considered that debonding affects the applied stress field by inducing stress gradients in the fiber and in the matrix. The probability of occurence of a further matrix crack $\left(\mathrm{P}_{M}\right)$ and the probability of failure of the fiber $\left(\mathrm{P}_{\mathrm{F}}\right)$ in the presence of matrix cracks were derived inserting relations describing the stress-state into a failure probability format. Characteristics of matrix cracking at saturation and of fibre failure were obtained from the comparison of $\mathrm{P}_{\mathrm{M}}$ and PF.

Figure 5 thus confirms the above classification of materials as a function of the stressstrain behavior and of interfacial resistance. For important debond, $\sigma_{\mathrm{s}}$ appears significantly different from $\sigma_{R}$, and the number of matrix cracks is small. This is indicative of a limited non-linear domain and a significant hardening domain as observed with the materials of the first family having weak interfaces.

On the contrast for shorter debond, $\sigma_{\mathrm{s}}$ increases up to $\sigma_{\mathrm{R}}$ and the number of matrix cracks becomes tremendously important. The matrix cracking phenomenon tends to be limited by fiber failure. This reflects the presence of a broad non-linear domain as observed with materials of the second family possessing strong interfaces.

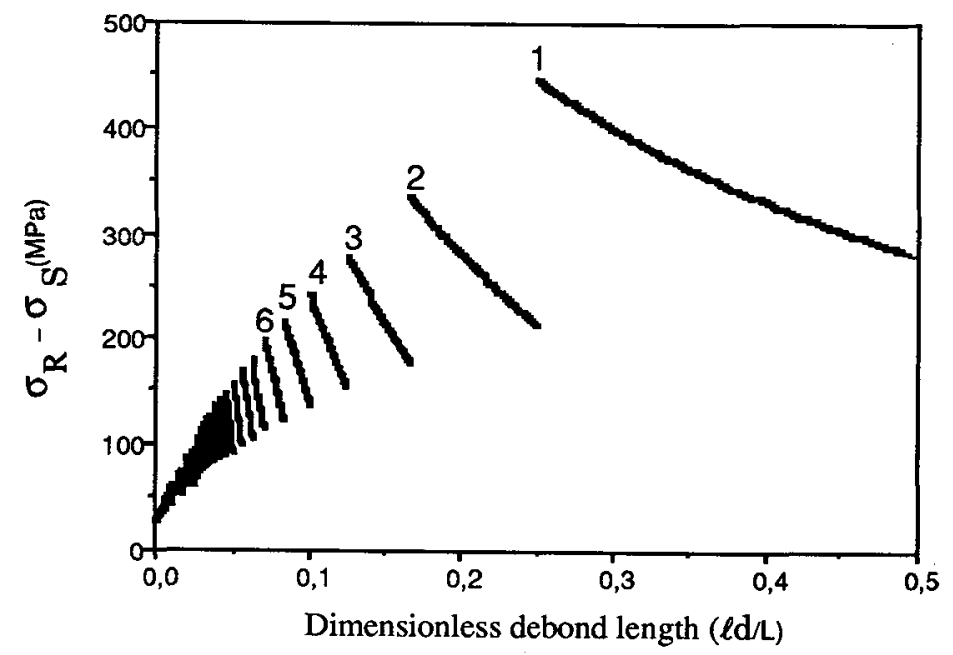

Figure 5: Predictions of debond length influence on the quantity $\sigma_{R}-\sigma_{\mathrm{S}}$ (ultimate strength - stress at matrix cracking saturation), and on the associated number of matrix cracks. 


\section{INFLUENCE OF INTERFACES ON FRACTURE TOUGHNESS}

The toughening mechanism based upon fiber pull-out and crack bridging and requiring weak interfaces has been extensively discussed in the literature for undirectional CMC. 2D woven composites such as those processed by CVI seem to be more promising to meet the interfacial requirements for both strong and tough composites. Toughening involves a large amount of cracks created at the tip of the main failure crack. These cracks form a process zone inducing a significant R-Curve effect. At a maximum strain energy release rate $G_{\max }$, a major crack propagates as a result of failure of fibers within the bundles.

Incidence of interfacial resistance upon strain energy release rate at instability $G_{\max }$ (measuring fracture toughness) was demonstrated using experimental data obtained on the previously mentioned $\mathrm{SiC} / \mathrm{SiC}$ composites (table 2) using CT specimens [14]. Figure 6 shows that fracture toughness data can also be grouped into two families coincident with those described in the second section :

- the high fracture toughness data obtained with the materials possessing strong interfaces.

- and the low fracture toughness data obtained with those materials possessing weak interfaces.

Within each family, the fracture toughness level is dictated by the size of the process zone. For a given process zone size, at a given initial notch length a higher fracture toughness is observed for the materials possessing strong interfaces. This result may be logically attributed to a higher density of cracks in the process zone favored by interfaces, as indicated by the short crack spacing distance at saturation $\left(l_{\mathrm{S}}\right)($ table 2$)$.

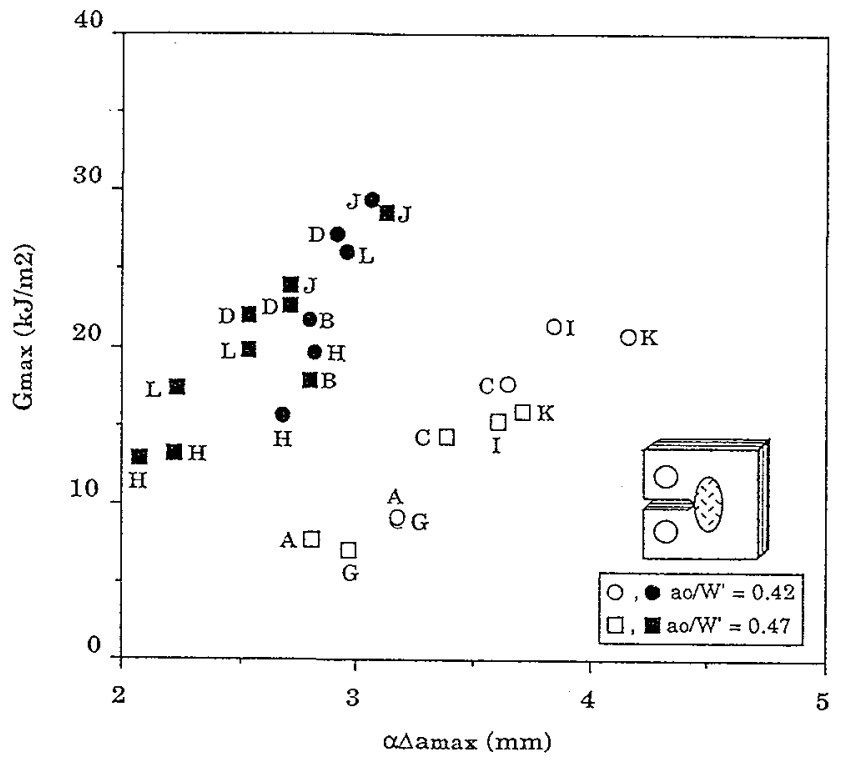

Figure 6: Plot of fracture toughness at instability for the different $\mathrm{SiC} / \mathrm{SiC} \mathrm{CVI}-$ composites, as a function of the process zone size $\alpha \Delta \mathrm{a}_{\max }$. 
A larger process zone is required to get identical fracture toughness with the materials possessing weak interfaces. This effect is again related to matrix cracking. The crack spacing data given in table 2, show that crack density is lower in these latter composites. Therefore, the appropriate amount of cracks form now a process zone wider than in the materials possessing strong interfaces.

It is worth mentioning that fractographic examination of specimens by Scanning Electron Microscopy revealed that the tougher composites exhibited pull out lengths significantly smaller $(<100 \mu \mathrm{m})$ than those observed in the weaker ones $(>200 \mu \mathrm{m})$. This result suggests that the contribution of fiber sliding to toughening was low relative to matrix cracking influence.

This incidence of interfaces through matrix cracking is described by the following equation for strain energy release rate in materials possessing a process zone [6] :

$$
\mathrm{G}=\frac{\mathrm{P}^{2}}{2 \mathrm{~B}} \frac{\mathrm{C}}{\mathrm{Co}(\mathrm{ao})} \frac{\delta \mathrm{Co}(\mathrm{ao})}{\delta \mathrm{a}}
$$

where $\mathrm{P}$ is the applied load, $\mathrm{B}$ is specimen width, $\mathrm{C}$ is the specimen compliance and $\mathrm{Co}(\mathrm{ao})$ is the reference elastic compliance of specimen having an initial notch length ao.

Equation (2) shows that $G$ is commensurate with the degree of damage through specimen compliance $\mathrm{C}$. Therefore it is evident that significant toughening is enhanced by dense matrix cracking and thus by strong interfaces.

\section{CONCLUSIONS}

Various interfacial mechanisms are assumed to occur as matrix cracks, including debonding and subsequent sliding of the fiber against the matrix. Toughening in unidirectional CMC is attributed to this latter mechanism by many researchers.

It was shown in the present paper that interfaces control the matrix cracking phenomenon. Therefore they determine the specific features of the stress-strain behavior.In the presence of strong interfaces, the stress-strain behavior of CMC exhibited an important non-linear domain reflecting multiple cracking, and high stresses. This trend was evidenced experimentally on microcomposites specimens, and described quantitatively using a failure model based upon fracture statistics. The advantage shown by composites with rather strong interfaces was confirmed by fracture toughness data and by a strain energy release rate equation which indicated that toughness is enhanced by multiple matrix cracking at notch or crack tip.

\section{ACKNOWLEDGMENTS}

This review uses results generated within the frame of various research works supported by SEP and CNRS through grants provided to students (C. Droillard, L. Guillaumat, N. Lissart, P. Voisard, C. Heibst, C. Rechiniac, F. Rebillat).

\section{REFERENCES}

[1] Kerans R.J. and Parthasarathy T.A., J. Amer. Ceram. Soc. 74 (1991) 1585-96.

[2] Verpoest I., Desager M. and Keunings R., Controlled Interphases in Composite Materials, (Matsuo Ishida, Ed) Elsevier Science Publishing Co., Inc. (1990) 653666. 
[3] Rechiniac C., Lissart N., Lamon J., Corne P. , Proceedings of the Fifth European Conference on Composite Materials, ECCM 5- Bordeaux (1992) (Bunsell et al. eds) EACM-EEC, Bordeaux (1992) 895-900.

[4] Evans A.G., J. Amer. Ceram. Soc. 73 (1990) 187-206.

[5] Droillard C., Yemsi Y., Lamon J. , ibid. ref 3, 787-792.

[6] Droillard C., Voisard P., Heibst C., Lamon J.to be published.

[7] Naslain R. , Langlais F., Tailoring Multiphase and Composite Ceramics (R.E. Tressler, ed.), Mat. Sci. Research, 20, Plenum Press, New York, (1986) 145-64.

[8] Thouless M.D , Sbaizero O., Sigl L.S., and Evans A.G., J. Amer. Ceram. Soc. 72 (1989) 525-32.

[9] Evans A.G., Marshall D.B., Acta Metall., 37 (1989) 2567-83.

[10] Cao H.C. , Bischoff E., Sbaizero O., Rühle M., Evans A.G., Marshall D.B., Brennan J.J. , J. Amer. Ceram. Soc. 73 (1990) 1691-99.

[11] Lamon J., Rebillat F., Evans A.G., to be published.

[12] Lamon J., Lissart N., Rechiniac C., Roach D.H., Jouin J.M. Proc. 17th Annual Conference and exposition on Composites and Advanced Ceramics, 10-15 January 1993, Cocoa Beach, Florida (USA), Amer. Ceram. Soc. (in press).

[13] Lamon J., Guillaumat L., ibid. ref 3 , 585-590.

[14] Droillard C., Lamon J. to be published. 